\title{
EGU2020-20061
}

https://doi.org/10.5194/egusphere-egu2020-20061

EGU General Assembly 2020

(c) Author(s) 2020. This work is distributed under

the Creative Commons Attribution 4.0 License.

\section{Active deformation evidence in the offshore of western Calabria (southern Tyrrhenian Sea) from ultra-resolution multichannel seismic reflection data: results from the Gulf of Sant'Eufemia}

\author{
Fabrizio Pepe ${ }^{1}$, Mor Kanari ${ }^{2}$, Pierfrancesco Burrato ${ }^{3}$, Marta Corradino ${ }^{1}$, Henrique Duarte ${ }^{4}$, Luigi \\ Ferranti ${ }^{5}$, Carmelo Monaco ${ }^{6}$, Marco Sacchi ${ }^{7}$, and Gideon Tibor $^{2}$ \\ ${ }^{1}$ Dipartimento di Scienze della Terra e del Mare, Università di Palermo, Italy \\ ${ }^{2}$ Israel Oceanographic \& Limnological Research, Haifa, Israel \\ ${ }^{3}$ Istituto Nazionale di Geofisica e Vulcanologia, Roma - Italy \\ ${ }^{4}$ Marine Department, Geosurveys - Geophysical Consultants Lda, Aveiro, Portugal \\ ${ }^{5}$ Dipartimento di Scienze della Terra, dell'Ambiente e delle Risorse, Università di Napoli "Federico II", Napoli, Italy \\ ${ }^{6}$ Dipartimento di Scienze Biologiche, Geologiche ed Ambientali, Università degli Studi di Catania, Catania, Italy \\ ${ }^{7}$ Consiglio Nazionale delle Ricerche - Istituto di Scienze Marine, Sede secondaria di Napoli, Napoli, Italy
}

An ultra-resolution, multichannel seismic reflection data set was collected during an oceanographic cruise organised in the frame of the "Earthquake Potential of Active Faults using offshore Geological and Morphological Indicators" (EPAF) project, which was founded by the Scientific and Technological Cooperation (Scientific Track 2017) between the Italian Ministry of Foreign Affairs and International Cooperation and the Ministry of Science, Technology and Space of the State of Israel. The data acquisition approach was based on innovative technologies for the offshore imaging of stratigraphy and structures along continental margins with a horizontal and vertical resolution at decimetric scale. In this work, we present the methodology used for the $2 \mathrm{D}$ HR-seismic reflection data acquisition and the preliminary interpretation of the data set. The 2D seismic data were acquired onboard the R/V Atlante by using an innovative data acquisition equipment composed by a dual-sources Sparker system and one HR 48-channel, slant streamers, with group spacing variable from 1 to 2 meters, at $10 \mathrm{kHz}$ sampling rate. An innovative navigation system was used to perform all necessary computations to determining real-time positions of sources and receivers. The resolution of the seismic profiles obtained from this experiment is remarkable high respect to previously acquired seismic data for both scientific and industrial purposes. In addition to the seismic imaging, gravity core data were also collected for sedimentological analysis and to give a chronological constraint using radiocarbon datings to the shallower reflectors. The investigated area is located in the western offshore sector of the Calabrian Arc (southern Tyrrhenian Sea) where previous research works, based on multichannel seismic profiles coupled with Chirp profiles, have documented the presence of an active fault system. One of the identified faults was tentatively considered as the source of the Mw 7, 8 September 1905 seismic event that hit with highest macroseismic intensities the western part of central Calabria, and was followed by a tsunami that inundated the coastline between Capo 
Vaticano and the Angitola plain. On this basis, the earthquake was considered to have a source at sea, but so far, the location, geometry and kinematics of the causative fault are still poorly understood. In this study we provide preliminary results of the most technologically advanced ultra-high-resolution geophysical method used to reveal the 3D faulting pattern, the late Quaternary slip rate and the earthquake potential of the marine fault system located close to the densely populated west coast of Calabria. 